\title{
Funding Strategies for Agricultural Research Challenges
}

\author{
Charles E. Hess \\ Environmental Horticulture, University of California, Davis, CA 95616
}

Change is occurring at an incredible pace in agriculture and specifically in the horticultural world. For example, rapid advances in molecular biology mean that we now can ask, and answer, questions that were not possible before. Basic, fundamental questions have very near-term practical applications, especially since the speed at which basic research is applied also is increasing. Everywhere you look, exciting things are going on, both in molecular biology and in basic plant sciences. And more is yet to come!

\section{FUNDING}

Just about any discussion of agricultural research these days eventually comes around to talking about how we are going to pay for it, so I'm going to put it right up front. Things have not changed very much since 1776 when the famous Scottish economist Adam Smith wrote, "No complaint is more common that that of a scarcity of money." We certainly can identify with that sentiment today as public-sector research is tugged back and forth by various constituencies, and at the same time is faced with the necessary economic policy of reducing the deficit. These fiscal realities make it even more necessary for us to take into account outside forces, what the economists call "externalities," that influence our issues, our goals, and our funding.

\section{EXTERNALITIES}

Over the years, I have concluded that if we truly want to understand the forces at work in motivating agricultural research and influencing its efforts to improve agriculture and its products, we must go beyond a simple preoccupation with the science involved. There are powerful externalities that supersede the control of individuals and even of institutions. They create pressure, they influence policy, and they determine funding.

These externalities affect not only the way in which we do our work but what work we decide to do. Research policy is not formulated in any pure and solitary test tube; it springs from the messy and often disorderly real world of conflicting demands and unclear choices. Scientists no longer operate, in fact, we probably never really did, in isolation from an increasingly concerned and aware public. Our course is influenced continually by the changing winds of public opinion and national and agricultural policy.

Some 40 years ago, when a national farm bill was formulated, only three or four major groups were involved. Today, $>215$ groups with active interests make their voices heard and help shape policy. We must keep the public's priorities, needs, desires, and concerns in mind, and work to make them more aware of ours.

Clearly, our ability to tap the full potential of technology depends on a reservoir of knowledge in the basic and applied sciences of agriculture. To achieve increased funding to pursue this knowledge, we must approach research priorities from the standpoint of how the research, teaching, and extension will benefit society. From my perspective, the horticultural sciences have a tremendous amount to offer in creating plants that will help to meet many of the crucial needs of our time.

\section{COMPETITIVENESS}

For example, look at the current focus by the public and by Congress on the importance of international competitiveness and the U.S. trade deficit. These concerns are pushing research to play a vital role in such areas as reduced production costs and enhanced product quality. We need every ounce of careful management and efficient technology we can muster to maintain our competitiveness in a tough global marketplace and at the same time have environmentally sensitive agriculture.
This approach will be especially crucial if the United States succeeds in negotiating a level playing field for world trade at the ongoing General Agreement on Tariffs and Trade (GATT) talks. The United States cannot compete on the basis of low labor costs or cheap land costs. We will have to compete on the basis of our technology to maintain our low per-unit production costs, which still are among the lowest in the world.

These negotiations have particular importance for the horticulture industry because of the drive to achieve uniformity in regulations and to reduce trade barriers. Floriculture in general, and foliage plants in particular, have had competition from Latin America, where low labor costs and in some cases, climate, make it possible to produce plants at very low cost.

The United States has erected barriers to importation on the grounds that we do not want to import plant pests. That is a very valid concern, but I have a feeling that sometimes such phytosanitary issues are used as a trade barrier. If we really want an open market with free trade, we cannot use trade barriers and expect other nations to drop theirs. We must become more efficient than our competitors on the basis of better technology, or if that is not possible, grow a crop that is different from what is marketed now or in a form more appealing to the consumer, or more nutritious.

\section{ENVIRONMENT}

The environment is another major area in which national policy and the public agenda influence science policy and research. Environmental concerns were strongly reflected in the 1985 Farm Bill, and they are even more strongly present in the current farm legislation.

Through technology, the United States has developed the most efficient food, fiber, and forest system in the world. For example, the latest figures show that the average U.S. consumer spends only $11.8 \%$ of his or her disposable income for food. But we now recognize that technology has costs that were not fully anticipated at the time of its introduction. As science has fine-tuned its instrumentation and its abilities to track and detect smaller concentrations of contaminants in our food, our ground water, and our environment, the public is becoming more and more sensitive to the social, environmental, and health implications of agriculture, and is more and more vocal about it.

It is time for those of us in agriculture to be proactive rather than defensive. Not only does our future ability to produce food and fiber depend on it, but to do otherwise is to invite restrictive legislation and regulation that may remove our decision-making power and constrain our flexibility to adopt management practices that best fit each farming situation. There is the feeling among some that agriculture must be regulated into environmental concern. This is not the case, nor would it be in the long-term interest of our nation to do so.

\section{SUSTAINABLE AGRICULTURE}

Overall, agriculture endeavors to operate in an environmentally responsible fashion, while continuing to produce economically and profitably. Sustainable agriculture is most emphatically not a return to the "low-tech" production methods of the 1930s. On the contrary, it is the use of the very best of technology in a balanced, well-managed, and environmentally responsible system.

\section{WATER QUALITY}

One of the reasons that sustainable agriculture is coming to the fore is a very real public concern about reports of contamination of the nation's ground and surface water resources by agricultural 
chemicals and nutrients. That concern is justified. For example, a United States Geological Survey report published a year ago showed that in a sampling of surface water in 10 midwestern states, $90 \%$ of the samples showed the presence of some agricultural chemicals. Also, the Environmental Protection Agency has completed fieldwork and analysis on a major survey of well-water quality nationwide. Although the number and amount of pesticides found were low, $\mathrm{N}$ was found in $50 \%$ of the samples.

President Bush has identified protection of the nation's water resources as a high-priority item and has made it clear that farmers ultimately are responsible for avoiding contamination of water as a result of their land-management practices (including container production of nursery crops). He has given the U.S. Dept. of Agriculture (USDA) a lead role in research and education and in the implementation of plans to improve water quality. We saw an expenditure of $\$ 155$ million in 1990 and a budget of $\$ 207$ million in 1991.

The President's Water Quality Initiative combines the expertise of agencies government-wide to provide farmers, ranchers, and foresters with the knowledge and technical means to respond independently and voluntarily to on-farm environmental concerns and related state water quality requirements. The USDA wants to achieve this goal in a way that reduces the need for restrictive regulations, maintains agricultural productivity, avoids economic hardship, and sustains an economical and safe supply of food and fiber.

\section{FOOD SAFETY}

In addition to their water quality concerns, many Americans are concerned about the safety of the food they eat. They are increasingly anxious about conflicting reports regarding pesticides, chemicals, and residues. The public perception of chemical residues in food items, especially fresh fruits and vegetables, has caused widespread public alarm and brought about major disruption of markets.

Yet, the balance between risk and safety has been tipping too far in one direction. We must remind the public that we do not live in a totally risk-free environment, that one in a million are not bad odds. We also need to stress that our incredibly low food costs are very dependent on the use of technology and that a decrease in the use of chemicals such as fungicides actually can reduce food safety by a corresponding increase in naturally occurring toxins such as aflatoxin. We need to reduce chemical use, yet prevent the spread of new pests and diseases. Research has a role to play in both areas.

During the current fiscal year, the USDA is launching a program to determine the facts of the food safety issue. Our multi-agency effort will collect and analyze residue data regarding actual exposure levels in fresh fruits and vegetables. This will enable us to deal with facts rather than speculation.

Another example, in which many of you participate, is the InterRegional Project \#4 (IR-4) to obtain more prompt pesticide registrations for minor-use crops when such pesticides already are registered for use on other food or feed crops. We recognize that FIFRA's reregistration requirements are exacerbating the backlog, and we are increasing our pesticide clearance program research activities and streamlining the operation of the National Agricultural Pesticide Impact Assessment Program.

At the same time, we want to give increased emphasis to integrated pest management (IPM) and integrated crop management (ICM). This involves developing new systems of control as well as accelerating the adoption of existing programs. We also want to maximize biotechnology's potential to speed the development of genetic resistance to insects and disease. We can increase efficiency by cutting production costs and protect the environment by reducing heavy dependence on pesticides.

Let me stress that we are not seeking to eliminate the use of important chemicals and fertilizers. We appreciate that, in many instances, chemicals and fertilizers are absolutely necessary to the farmer. We are, however, seeking ways to reduce their usage and increase their effectiveness. We now must include environmental impacts in the cost/benefit equation of our production systems, something that has not always been considered.

\section{GLOBAL CLIMATE CHANGE}

On an even larger scale, the public is paying close attention to the role agricultural practices play in global climate change. It is a high priority in Congress, the Office of Science and Technology Policy, and agencies across the government. While there still is considerable debate about whether there actually will be climate change or global warming, there is no question that we have dramatically increased the levels of $\mathrm{CO}$, and other greenhouse gases with potential to modify our environment. For example, we know from horticultural research that $\mathrm{CO}$, enrichment of the atmosphere in a greenhouse increases plant growth and development.

Agriculture in general and horticulture in particular have three important roles to play in global climate change. In the first place, we clearly contribute to the accumulation of greenhouse gases through the production of methane by livestock and flooded-field rice, and of NO, as a by-product of $\mathrm{N}$ fertilization. Research on more efficient fertilization practices would help reduce these gaseous by-products, as well as decrease potential groundwater contamination by fertilizers.

The second role of agriculture is to adapt if there is climate change. We can do that through the development of stress-resistant plants, adding traits such as drought, temperature, and salinity tolerance to crops. Results of this type of research already have extended the range of climates in which we are able to grow selected plants.

Third, is the very positive role plants can play in mitigating the potential of climate changes by sequestering $\mathrm{CO}$, through the process of photosynthesis. In addition, trees and other plants can be a source of biomass as alternative fuels and for carbon-based chemical feedstocks used in the industry, recycling $\mathrm{CO}_{2}$, as well as replacing fossil fuels, the use of which simply adds more $\mathrm{CO}$, to the environment. Environmental horticulture plays a key role in urban areas by providing shade and natural air conditioning, thus reducing energy demands.

\section{STRATEGIES FOR FUNDING}

You may be saying at this point, "I thought you were going to write about funding strategies." Well, I am, and actually I have been. I have given you some of the issues that are major concerns of the public, the administration, and Congress. If you want to be successful in stiff competition for scarce financial resources, you have a much better chance of gaining support if you can address these issues and others that you may identify. I have given you some examples of how horticulture can serve society and justify an increased investment in research.

I will, however, suggest two possible funding strategies for your consideration. You already are well on the road of one of themyou were tremendously supportive of our efforts for the National Research Initiative (NRI). I hope you will continue your commitment in coming years.

The 1990 Farm Bill authorizes full funding of the initiative at the recommended level of $\$ 500$ million by fiscal year 1995 . In the appropriation process, which is key to funding, we were successful in launching the initiative at $\$ 73$ million. This represents about $\$ 31$ million in truly new money because the original competitive grants program of about $\$ 42$ million is incorporated into the initiative. Although we had hoped to reach $\$ 100$ million in the first year, we are pleased with the increase. The tremendous effort that went into bringing the need for a new research investment to the attention of Congress has helped to raise the visibility of the total science and education $(\mathrm{S} \& \mathrm{E})$ research budget.

We promised that the NRI would not be at the expense of existing research programs such as formula funding. And it was not! In fact, Congress, through your help and support, provided the best S\&E budget in recent memory. I say "Congress," because the fact of life is that while the Administration proposes, Congress disposes.

The overall S\&E budget went from $\$ 1.232$ billion to $\$ 1.400$ billion, an increase of $\$ 168$ million or $12 \%$. There were increases in Hatch, Smith-Lever, and McIntire-Stennis funding. There is more money for the National Agricultural Library and the Agricultural 
Research Service (ARS), including the National Seed Laboratory and Beltsville. So you can see what can be done when we all work together in a common interest-increasing the investment in research for society's ultimate benefit.

I want to mention one strategy used this year to get input on research priorities that accurately reflect the interests of the users of the research information. We set up workshops involving crosscutting commodity areas including animals, fiber and oil seed crops, feed grains, horticulture, and forestry to discuss the NRI and the base research programs in the USDA. The workshops reviewed the program plan of the NRI and made recommendations, and the results were used by the research committees and the Competitive Grants Office staff to develop requests for proposals. These were approved and published in the Federal Register.

I mention this process because it is how we are attempting to get as much input as possible to reflect research needs without having a separate line in the budget to represent every individual commodity in agriculture. Many groups would like to see their interest specifically represented, but that approach typically becomes more divisive than supportive.

It took a tremendous amount of work and cooperation to get the NRI through, particularly in this time of new deficit reduction measures. Now that domestic spending is slated to increase by inflation only, we must continue to work together to present a unified proposal to the USDA, the Office of Management and Budget (OMB), and Congress.

I want to mention a second strategy for your consideration. Working with other professional societies, you should make your research needs known and work with the research base rather than a separate initiative. For example, the American Assn. of Nurserymen has done an excellent job in promoting the nursery industry's need for increased engineering research on equipment to handle plants. In addition, joint private sector/ARS efforts in new crop development have been very successful, and of course, similar approaches can be made at the state level. I do not know how much ASHS has worked with the trade organizations, but perhaps you can play a leadership role in that area as one way of developing an industrywide approach.

Once priorities have been established and communicated to the USDA on the national level (as well as on the state level), it is important to have a presence on Capitol Hill for example, a Congressional Fellow. It also is helpful to cultivate an awareness of your interests among congressmen who have a keen interest in horticulture and can be your advocates. When you can put together an integrated plan that involves the USDA, OMB, and Congress, you have the best chance for success. An end run, going it alone, can work, but usually only once for a particular area of interest, and generally at someone else's expense. This is particularly true with the new budget agreement.

\section{PUBLIC PERCEPTION OF TECHNOLOGY}

There is one other externality I want to share with you. It is one that we all have to take an active part in facing-the growing antiscience, anti-technology attitude on the part of some members of the public. It is ironic that some of the best new tools we have to help address the challenge of feeding and clothing a growing world population on a finite amount of land in an environmentally sensitive manner are being attacked under the banner of environmental, economic, and social concerns. For example, with all the possible benefits of biotechnology, anxiety on the part of a concerned public still exists. And unfortunately, it often is based upon the perception of risk rather than the reality.

To my mind, this is one of the single most critical issues confronting us today. Some people seem to forget that the ultimate beneficiary of research and technology that increases food production efficiency is the consumer, who enjoys inexpensive, wholesome, and safe food that can be produced in a way that is environmentally sound.

Not only is irrational fear disrupting domestic markets, but its influence is international as well. Some in the European Community are attempting to add a fourth criterion to technology regulation. Along with safety, efficacy, and purity, they now want to use social and economic impacts as a regulatory control. It is true that social and economic impacts of new technology are valid issues, but they should be approached by research, not by regulation. First determine if there is an impact, and then take steps to mitigate it. But do not regulate technology out of existence.

\section{CONCLUSION}

Research and sound science are at the base of a successful agriculture, and we in the United States cannot rest on our proverbial laurels. When it comes to nondefense $\mathrm{R} \& \mathrm{D}$ expenditures as a percent of gross national product, Japan, West Germany, and France all are ahead of us. At a recent Brookings Institution seminar on competitiveness, several panelists agreed that the United States is in for stiff high-tech battles with the more unified European Community, which will come about with EC 92.

We simply cannot afford to underinvest in research, especially in agricultural research, which has such a high investment : return ratio. This includes making the effort to attract top-notch young men and women into science and to increase the racial, cultural, and gender diversity of that brain pool.

Whatever our funding, none of our plans can be fully realized without people to carry out those plans. The nation's scientific base is eroding, and student interest in the plant sciences continues to decline. It is an anomaly that this is happening at the very moment when the plant sciences are poised to enter such electrifying times and make such exhilarating discoveries. We must communicate this excitement to young people, educate them as they are making their college, course, and career choices.

My own experience has been that the more people understand about science, the more they are interested in it, feel positive about it, and are willing to support its funding. And we cannot afford to have research progress preempted by prohibitions, or endangered by irrational public concerns.

We need more scientist/communicators like the late Sir Peter Medawar. I am not talking simply about his Nobel prize-winning work, but about his passion to, as one reviewer put it, "explain his work and his world to the rest of us." People can't generally understand science unless scientists make it understandable. As a society and as a profession, we have to recognize the people who do a good job of communicating to the public the benefits of the work we are doing.

The rewards of successful communication can be tremendous. When a consumer or a legislator is knowledgeable and informed, the word technology in connection with food should not raise a red flag of fear, but rather conjure up thoughts of lower food costs, safer food, more nutritious food supplies, and a healthier environment. "Natural" does not always mean good, and "technology" does not always mean bad. 